Original Article

\title{
A PILOT INVESTIGATION INTO ASSOCIATIONS BETWEEN VARIOUS INDOOR AIRBORNE FUNGAL PARTICLES IN TRIPLICANE PUBLIC TOILET OF CHENNAI, TAMIL NADU
}

\author{
KM. RUBAB ANJUM, K. SIVAKUMARI, K. ASHOK*, S. RAJESH \\ PG and Research Department of Zoology, Presidency College, Chennai, Tamil Nadu, India \\ Email: msivakumari@rediffmail.com
}

Received: 28 Dec 2016, Revised and Accepted: 20 Mar 2017

\section{ABSTRACT}

Objective: To study and to explore the fungal species present in indoor toilet environment.

Methods: Lactophenol cotton blue staining.

Results: 5 fungi isolates belonging to 5 genus were identified namely Aspergillus niger, Aspergillus fumigates, Aspergillus flavus, Aspergillus terreus and Rhizopus oryzae.

Conclusion: In order to improve the quality of indoor toilet environment regular cleaning and disinfection should be done daily.

Keywords: Lactophenol cotton blue staining and Aspergillus species

(C) 2017 The Authors. Published by Innovare Academic Sciences Pvt Ltd. This is an open access article under the CC BY license (http://creativecommons.org/licenses/by/4.0/]

DOI: http://dx.doi.org/10.22159/ijcpr.2017v9i3.18891

\section{INTRODUCTION}

Fungal are ubiquitous in distribution and are a serious threat to public health in indoor environments $[1,2]$. Many fungi that are reported to cause allergy belong to Ascomycota, Basidiomycota or anamorphic fungi. Fungi are able to grow on almost all natural and synthetic materials, especially if they are hygroscopic or wet. Inorganic materials get frequently colonized as they absorb dust and serve as a good growth substrate for Aspergillus fumigatus and Aspergillus versicolor [2].

Wood is highly vulnerable to fungal attack. Cladosporium and Penicillium (Penicillium brevicompactum and Penicillium expansum) are reported to infest wooden building materials. Klin dried wood surfaces are more susceptible to fungi [3]. Acylated wooden furniture, wood polyethylene composites, plywood and modified wood products are susceptible to infestation by Aspergillus, Trichoderma and Penicillium [4].

Exposure to a variety of fungi such as Aspergillus spp. and Fusarium spp. may result in serious respiratory infections in immune-compromised persons [5-9]. People with impaired immune system who spend most of their time in indoor environments contaminated by fungi may develop serious fungal infections [10-11]. Chronic obstructive pulmonary disease, asthma, cystic fibrosis are disorders among persons potentially infected with Aspergillus [12]. In cystic fibrosis or asthma patients, Aspergillus spp. can develop allergic bronchopulmonary aspergillosis, invasive or semi-invasive pulmonary aspergillosis and pulmonary aspergilloma [13].

The fungal syndrome is characterised by the occurrence of unspecific symptoms. The analysis of microbial volatile organic compounds or even the use of specially trained sniffer dogs are some of the methods used to detect hidden mold growth. However, these methods have not been scientifically evaluated. The odour alone perceived by human beings is not reliable enough to detect mold damage. As far as the rehabilitation of the indoor environment is concerned, it has to be pointed out very clearly that microbial damage has to be removed. The extermination of microorganisms is often carried out, but this procedure is not sufficient because of non-viable spores, for example, keep their allergenic potential. The acuteness of the rehabilitation procedures is normally considered according to the extent of the microbial damage. Adverse health effects are supposed to be linked with microbial growth in indoor areas and are mostly related with mold growth. Allergies is a predominant condition which has to be mentioned, followed by toxic alveolitis and reaction like (allergic) bronchitis, chronic obstructive pulmonary diseases, as well as the aggravation of asthma. Infections by molds and bacteria are very rare, but persons with an immunodeficiency are especially susceptible to fungal infections.

It has been found that spores of fungi contain fungal toxins (mycotoxins), which are well known from food contaminations. It has however not been confirmed whether these mycotoxins show toxic effects if fungal spores are inhaled. On the whole, the dose relationship between the concentration of microbial particles already mentioned and the adverse health effects described is not very well established.

When sanitary effects are observed, the susceptibility of the individual is very often crucial. In view of this, my objective is to study and to explore the fungal species present in indoor toilet environment.

\section{MATERIALS AND METHODS}

\section{Fungal collection}

The number and type of fungal species present in Triplicane public toilet were investigated and the study was conducted during the months of June to July 2016. A total of nine samples were collected in duplicate from the different sires of Triplicane public toilet.

\section{Isolation and identification of fungal species}

The numbers of fungi present in toilet environment were studied by exposing Sabouraud Dextrose Agar plates for $48 \mathrm{~h}$ and after the exposure and collection, the plates were taken to the Microbiology laboratory and incubated at $37{ }^{\circ} \mathrm{C}$ for $48 \mathrm{~h}$ for $5-7 \mathrm{~d}$ for isolating fungi (fig. 1A-J).

Identification of fungi was done using the standard procedures of Cheesbrough (2000) [14]. The fungal cultures were identified by using Lactophenol cotton blue staining and microscopic characteristics [15]. 


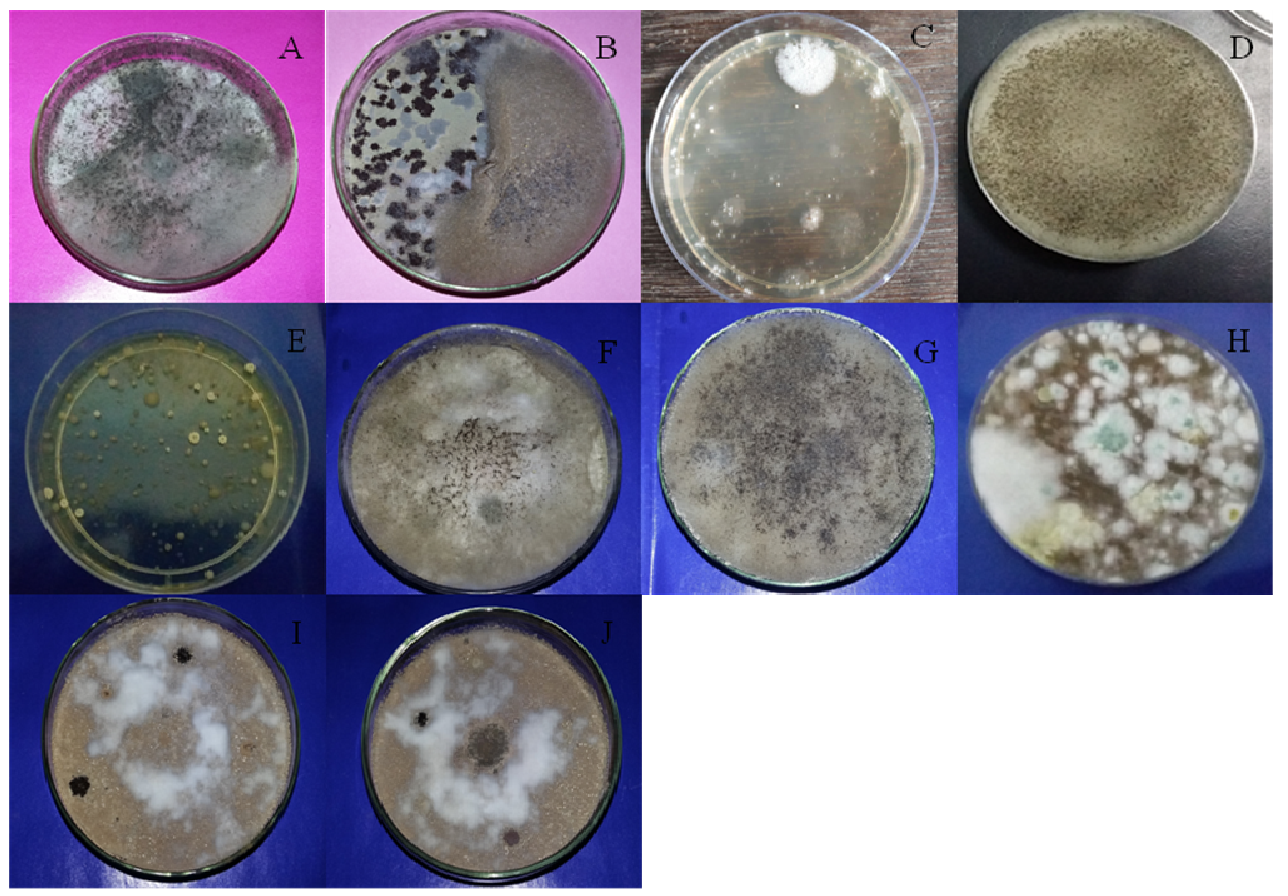

Fig. 1A, B, C, D, E, F, G, H, I and J Sabouraud dextrose agar (SDA) plates after $48 \mathrm{~h}$ of incubation in the indoor triplicane public toilet environment

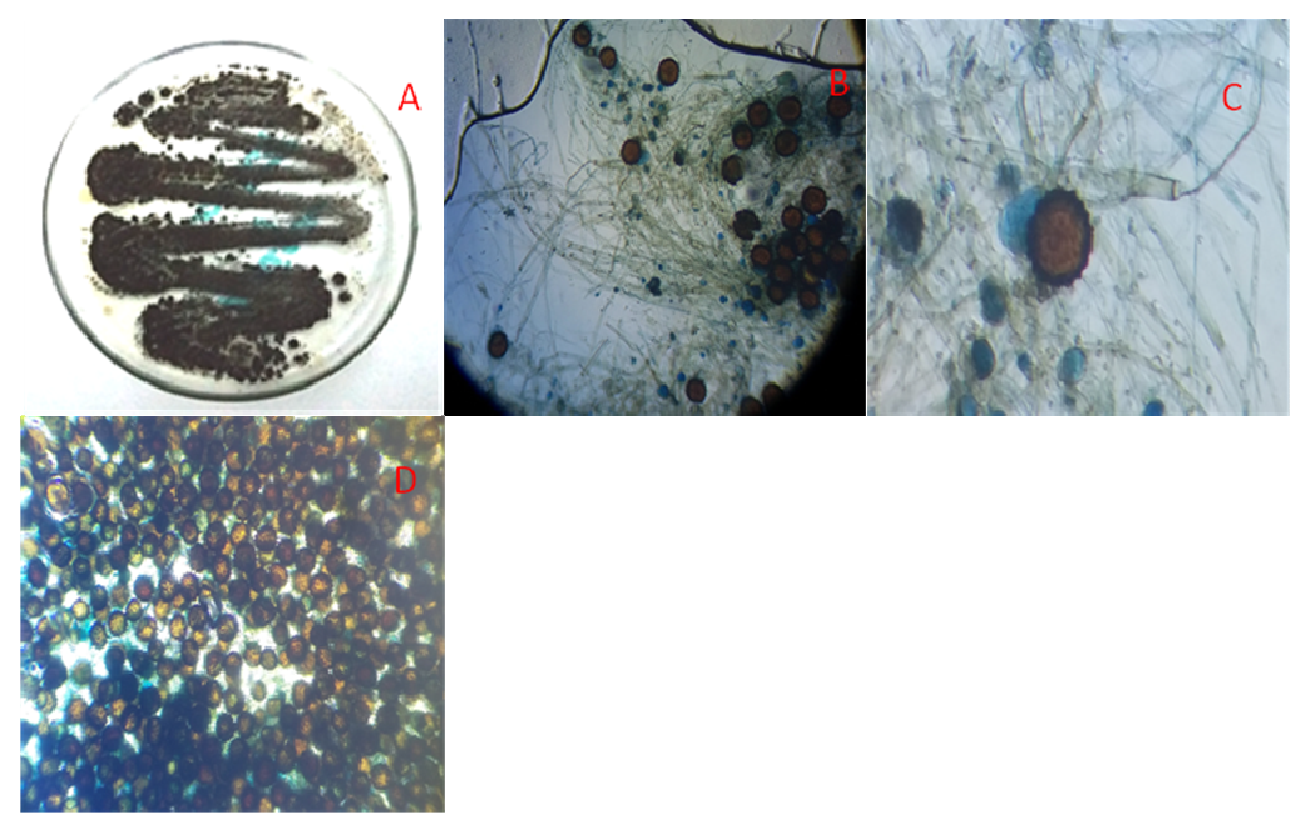

Fig. 2: (A) Single streak image of Aspergillus niger, (B-D) microscopic image of Aspergillus niger at 10 x magnification
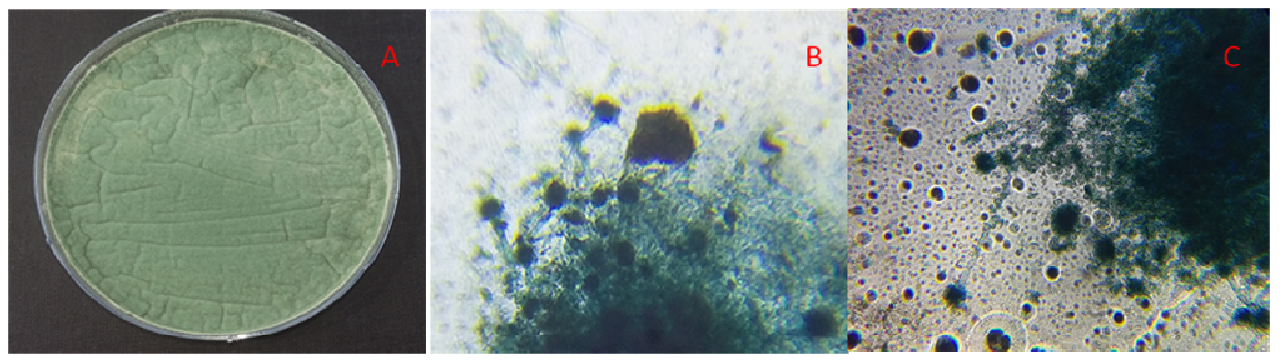

Fig. 3: (A) Single streak image of Aspergillus flavus, (B-C) microscopic image of Aspergillus flavus at $10 \mathrm{x}$ magnification 


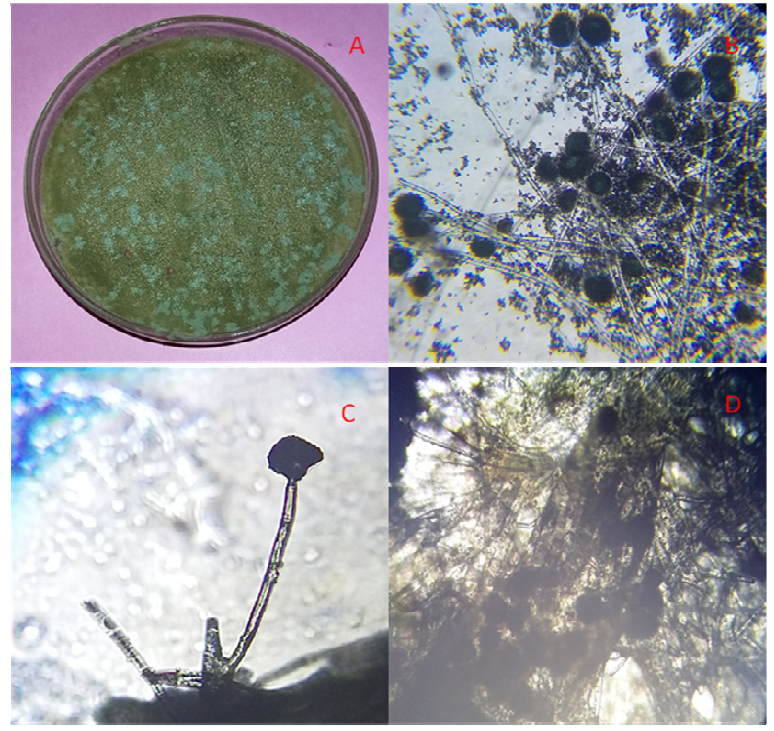

Fig. 4: (A) Single streak image of Aspergillus fumigatus, (B-D) microscopic image of Aspergillus fumigatus at $10 \mathrm{x}$ magnification

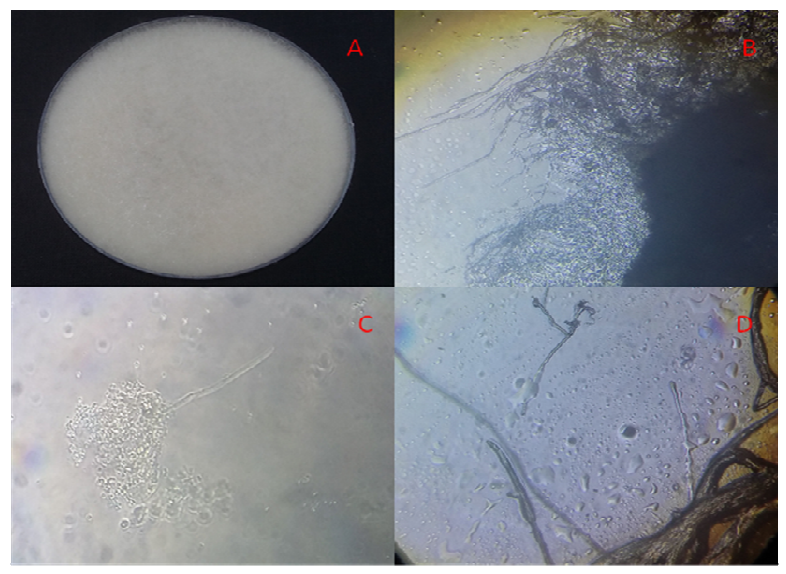

Fig. 5: (A) Single streak image of Rhizopus oryzae, (B-D) microscopic image of Rhizopus oryzae at $10 \mathrm{x}$ magnification

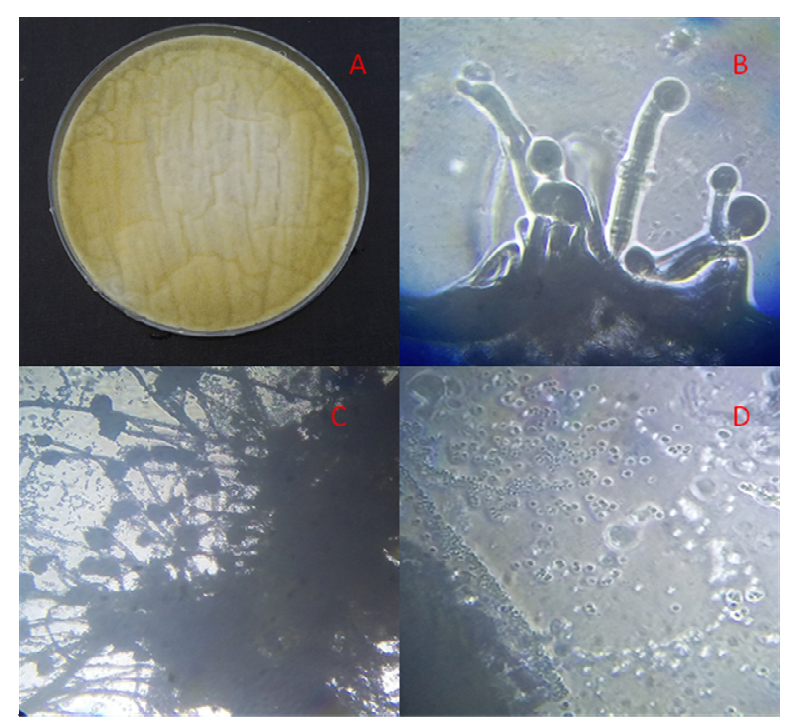

Fig. 6: (A) Single streak image of Aspergillus terreus, (B-D) microscopic image of Aspergillus terreus at 10 x magnification

\section{RESULTS AND DISCUSSION}

A total of 5 fungi isolates belonging to 5 genera were identified in this study as shown in fig. 2,3,4,5 and 6. Among them 4 isolates were filamentous fungi namely Aspergillus niger, Aspergillus fumigates, Aspergillus flavus and Aspergillus terreus and isolate one was Rhizopus oryzae. Since air does not contain any nutrients and has low moisture content it is not condusive to the growth and survival of microorganisms but it can act as an important medium for carrying and spreading of biological agents. The order of prevalence of air microflora is from highest to lowest in the toilet. The reasons for a high percentage of fungi in the toilets are due to the improper and low degree of hygiene and cleanliness because of minimal usage of disinfection procedures against airborne microorganisms which have given rise to bio-contaminants.

However, many fungal spores have the ability to cause allergies as well as other respiratory diseases and hypersensitivity reaction not only in immunosuppressed patients but also in healthy individuals. The fungi belonging to Aspergillus species can cause invasive Aspergillosis and produce mycotoxins which are known to be carcinogens [16]. Other fungal spores also have the ability to cause allergies as well as other respiratory diseases and hypersensitivity reactions not only in immunosuppressed patients but also in healthy individuals [17]. Hence, more attention should be given to safeguard indoor toilet environment otherwise, the growth of pathogenic microorganisms can cause toxigenic health hazards.

\section{CONCLUSION}

Indoor toilet environment plays important roles in human health. The health hazards posed by polluted indoor toilet environments include allergy, infections and toxicity. Fungi are ubiquitous in distribution and are a serious threat to public health in indoor toilet environments. In this communication, we have studied the current status on biotic indoor toilet air pollution, the role of fungi as biological contaminants and their impact on human health. In order to improve the quality of indoor toilet environment, regular cleaning and disinfection should be done daily.

\section{ACKNOWLEDGEMENT}

The authors are thankful to Dr. P. T. Devarajan, Department of Plant Biology and Plant Biotechnology, Presidency College, Chennai for the identification of isolated fungal species.

\section{CONFLICT OF INTERESTS}

Declare none

\section{REFERENCES}

1. Samet JM, Spengler JD. Indoor environments and health: Moving into the $21^{\text {st }}$ centuary. Am J Public Health 2003;93:1489-93.

2. Jarvis WR, Jarvis AA, Chinn RY. National prevalence of methicillinresistant Staphylocossus aureus in inpatients at the United States health care facilities. Am J Infection Control 2012;40:194-200.

3. Bush RK. Aerobiology of pollen and fungal allergens. J Allergy Clin Immunol 1989;84:1120-4.

4. Hoppe PR. Indoor climate. Experientia 1993;49:775-9.

5. Stark PC. Fungal levels in the home and allergic rhinitis by $5 \mathrm{y}$ of age. Environ Health Perspectives 2005;113:1405-9.

6. Larson EL, Morton HE. Disinfection, sterilization and preservation. Alcohols. Ed. Block SS. Lea and Febiger, Philadelphia; 1991. p. 91.

7. Dacarro C, Picco AM, Grisoli R, Redolfi M. Determination of aerial microbiological contaminations in scholastic sports environment. J Appl Microbiol 2003;95:904-12.

8. Newson R, Strachan D, Corden J, Millington W. Fungal and other spore counts as predictors of admission for asthma in the Trent region. Occup Environ Med 2000;57:786-92.

9. Ross MA, Curtis L, Scheff PA, Hryhorczyk DO, Ramakrishnan V, Wadden RA, et al. Association of asthma symptoms and severity with indoor bioaerosols. Allergy 2000;55:705-11.

10. Gorny RL, Dutkiewicz J. Bacterial and fungal aerosols in indoor environment in Central and Eastern European countries. Ann Agric Environ Med 2002;9:17-23.

11. Cox CS, Waters CM. Bioaerosols handbook. Lewis Publishers, New York; 1995. 
12. Muszyński A, Czerwińska A, Chruślińska I. Ocena jakości powietrza wewnętrznego pod względem mikrobiologicznym wpomieszczeniach dydaktycznych Wydziału Inżynierii Środowiska Politechniki Warszawskiej. Warsaw; 1992.

13. Lugauskas A, Krikštaponis A. Microscopic fungi found in libraries of Vilnius and factors affecting their development. Indoor Built Environ 2004;13:169-82.

14. Cheesbrough M. District laboratory practice in Tropical countries. Part 2 Cambridge Low price Editions; 2000. p. 3-8.

15. DeHoog GS, Guarro J, Gene J, Figueras MJ. Atlas of clinical fungi. Ed. 2. Centraalbureall voor Schiielcultures/Universitat Rovira i Virgili; 2000.
16. Trudeau W, Fernandes-Caldas E. Identifying and measuring indoor air biologic agents. J Allergy Clin Immunol 1994;94: 393-400.

17. Topbas M, Tosun I, Can G, Kaklikkaya N, Aydin F. Identification and seasonal distribution of airborne fungi in urban outdoor air in an eastern Black Sea Turkish town. Turk J Med Sci 2006;36:31-6.

\section{How to cite this article}

- KM Rubab Anjum, K Sivakumari, K Ashok, S Rajesh. A pilot investigation into associations between various indoor airborne fungal particles in triplicane public toilet of Chennai, Tamil Nadu. Int J Curr Pharm Res 2017;9(3):50-53. 